\title{
Los fundamentos de la gobernanza local para el desarrollo en países posbélicos: el caso de los Grandes Lagos Africanos.
}

\section{The foundations of local governance for development in post-war countries: the case of the African Great Lakes.}

Esta obra está bajo una Licencia Creative Commons Atribución 4.0 Internacional. DOI: https://doi.org/10.32870/sincronia.axxii.n74.32b18

\author{
Mulumeoderhwa Mufungizi Etienne * \\ Universidad Autónoma de Baja California \\ etienne.mulumeoderhwa@uabc.edu.mx \\ (MÉXICO)
}

\begin{abstract}
* Doctorante en Estudios del Desarrollo Global y profesor de Asignatura en la Facultad de Economía y Relaciones Internacionales de la Universidad Autónoma de Baja California. Es experto en estudios Regionales de África. Contacto: etienne.mulumeoderhwa@uabc.edu.mx
\end{abstract}

Recibido: $26 / 03 / 2018$

Revisado: $27 / 03 / 2018$

Aprobado: 04/06/2018

\section{RESUMEN}

Este artículo estudia el interés que ha tenido la gobernanza en las últimas décadas en los países posbélicos, específicamente en la región de los Grandes Lagos Africanos el caso de Ruanda y República Democrática del Congo. Demuestra en qué medida los usos y costumbres han sido la esencia de la gobernanza local para la resolusión de los conflictos violentos. También, estudia los procesos de desarrollo mediante la gobernanza en un contexto de la cooperación entre diferentes autores locales, regionales e internacionales.

Revisa cual es relación que tiene la gobernanza con el desarrollo y la seguridad en el periodo posconflicto entre los diferentes países que integran la región. En el mismo lineamiento, se ha retomado la cuestión de usos y costumbres para entender el desarrollo local en un marco cada vez más global. Este trabajo es resultado de una revisión de literatura de investigadores universitarios, de organizaciones regionales e internacionales para poder encontrar el hilo conductor para la reconstrucción de los países posconflictos. 
Palabras clave: La gobernanza. Usos y costumbres. Grandes Lagos Africanos. Ruanda. República Democráticas del Congo.

\begin{abstract}
The work presented addresses the interest that in postconflict countries has had governance in the last decades, especifically in the region of the african Great Lakes, especially in Rwanda and the Democratic Republic of the Congo. It showa to that extent the uses and customs have been the essence of local governance for the resolution of violence conflicts. It also seeks to study the processes of developpement through governance in a context of cooperation between local, regional and international actors.

It also review il linkage with developpement and security during the post-conflict period in the different countries that make up the region. The uses and customs have been used to understanding the developpement from the quotidianity in an increasingly global framework. This work is result of the reviewing of literature from academic researchers and from regional and international organizations in order to find the commun thread for the construction of post-conflict countries.
\end{abstract}

Keywords: Governance. Uses and customs. African Great Lakes. Rwanda. Democratic Republic of the Congo.

El siglo XXI no solamente se ha caracterizado por la aceleración de la evolución tecnológica y la globalización financiera sino que también ha sido caracterizado por las interdependencias entre las sociedades mismas que han cambiado la configuración de las instituciones así como las formas de pensar de la sociedades anteriores (Calame, 2003, p. 7). Esta ruptura de pensamiento ha favorecido la penetración del mercado y de las innovaciones científicas en los rincones de los pueblos posibilitando el contacto entre distintos actores.

Con esta tendencia, las referencias intelectuales, morales y políticas tradicionales han tendido a perder sustentos explicativos frente a los nuevos paradigmas. Los principios al nivel global han penetrado en los valores locales. En estas condiciones, ni los valores promovidos para la gobernanza, la evolución tecnológica, los medios de comunicación o del mercado parecen dar respuesta a una construcción de una sociedad de valores éticos. La rapidez con que se han dado los cambios en el ámbito social parece ser precipitada (Tony, 2014) sin ofrecer una alternativa (p.18). Esos cambios sociales se han acompañado por la desconfianza de la población hacia la élite política. 
En efecto, antes del siglo XXI el Estado había quedado el único regulador de la vida pública y del mercado. Muchos autores concuerden que el ámbito estatal se ha transformado integrando a distintas actores (Paquet, 1998, Calame, 2003; Koiman, 2003; Porras, 2016). En algunos países occidentales, la consolidación de las instituciones públicas como la consolidación de los mercados internos, han sido éxito de los gobiernos nacionales.

Los años 60's para el caso de los países africanos caracterizados por el periodo Posguerra y los nacionalismos que llevaron a las independencias, fueron otros los elementos que permitieron considerar al Estado como el único actor del desarrollo. Esta consideración no duró mucho tiempo. Las políticas estatales no correspondieron a las interdependencias que siguieron la globalización. El Estado se volvió burocrático, jerárquico y menos abierto a las dinámicas culturales.

Las nuevas dinámicas sociales plantearon una nueva concepción de la administración de los problemas sociales. Es cuando la gobernanza se plantea como la alternativa para resolver los problemas que conllevaban los cambios sociales. Esta alternativa consistía en las reformas estructurales y la inclusión de otros actores no estatales en la gestión de los asuntos públicos. Las reformas estatales tampoco dieron resultados esperados en los países en desarrollo como en caso de Ruanda y República Democrática del Congo.

Al inicio de los años 90's, la región de los Grandes Lagos Africanos vivieron los momentos más violentos de su historia. Éstos, fueron marcados por el genocidio ruandés entre Hutu y Tutsi pero también por las repetidas guerras de invasión de la República Democrática del Congo, países vecinos y las milicias internas. Dichos momentos de conflicto generaron un desequilibrio en la seguridad regional provocando un desplazamiento de la población.

En efecto, el conflicto de los Grandes Lagos Africanos (de aquí en adelante Grandes Lagos), iniciaron en Ruanda y tuvieron repercusiones en la República Democrática del Congo. El genecidio ruandés mandó a la República Democrática del Congo, miles de refugiados destabilizando así la estructura social de este último país. La presencia de los refugiados en las fronteras ruandesas justificó la invasión de la República Democrática del Congo. Los conflictos armados entre los dos 
países posibilitaron la creación de milicias de carácter etnico en la República Democrática como respuesta a la ocupación extranjera

De la misma manera, los conflictos armados en esa región tuvieron diferentes causas. Algunas causas fueron político-etnicas para el caso ruandés; mientras que las causas de los conflictos armados en la República Democrática fueron de carácter político y económico y de acceso a los recursos naturales estratégicos. Para resolver esos conflictos armados, muchos actores fueron obligados a sentar en la misma mesa para negociar. En las negociaciones de paz, actores de la sociedad civil, de los gobiernos, de los grupos armados asi como de la Comunidad Internacional fueron convocados. Cabe mencionar que diferentes mecanismos fueron puestos en marcha para eradicar los conflictos que vivió la región entre ellos están los usos y costumbres como la gobernanza para impulzar el desarrollo local.

En la actualidad, los conflictos disminuyeron, aunque quedaron algunas milicias que controlaron territorios enormes en la República Democrática del Congo. Los gobiernos centrales en los dos países de estudio centraron sus políticas en la mejora de la gobernanza y el desarme de las milicias. Ese proceso de acabar con los conflictos, implicó la participacion de actores estatales y actores privados que actuaron con lógicas diferentes pero vinculadas.

En efecto, la epoca posconflicto en los Grandes Lagos, se caracterizó por una sociedad civil que exigía a los gobiernos de poner en sus agendas la lucha contra la corrupción, la transparencia en la gestion de los asuntos públicos y la democracia (Anyang, 1999, p. 13).

La integración regional entre Ruanda y Zaïre (que aquí en adelante República Democrática del Congo) en la Comunidad Económica de los Países de los Grandes Lagos (CEPGL) fue el primer intento de gobernanza regional para resolver los problemas regionales. En este proceso de integración, la discusión sobre la seguridad fronteriza tuvo una atención particular ya que las milicias hutus ruandeses operaron desde las República Democrática del Congo para atacar a Ruanda pero también, este último país, apoyó rebeliones congolesas contra el gobierno congolés. Ruanda 
como la República Democrática del Congo, en su relación puso importancia en el comercio regional, la seguridad en la fronteras y poco hizo para fortalecer la gobernanza regional.

Otro elemento que motivó la creación de la Comunidad Económica de los Países de los Grandes Lagos, fueron los valores culturales que comparten esos países. Las mismas estructuras sociales se encuentran en los dos países, las cuales permitieron la creación de instituciones regionales en materia de educación, telecomunicación y mecanismos de paz o de la Sociedad Internacional de electricidad vinculadas directamenta a la Comunidad Económica de los Países de los Grandes Lagos. En ellas, los tres países gozaron de los mismos derechos de igualdad e integraron diferentes actores para llevar a cabo las metas que los dos Estados habían venido planteando: el desarrollo regional. A parte de ser una integración regional abierta a otros Estados, recibió la participación de actores de la sociedad civil, de las Organizaciones de Naciones Unidas, del Banco Africano de Desarrollo, del Banco Mundial y del Fondo Monetario Internacional, así como de las instituciones intergubernamentales de los países miembros (Comunidad Económica de Estados de África Occidental, 2016).

La pregunta principal puede formularse de esta manera: ¿En qué medida los usos y costumbres son fundamentos de la gobernanza en los países posbélicos? De la pregunta surge el argumento principal ya que los usos y costumbres, son fundamento esencial de la gobernanza local en los países posbélicos, en la medida en que son expresiones de la autonomía y autoderminación de los pueblos.

A partir de pregunta de investigación que plantea este problema, la literatura existente sobre la gobernanza en los Grandes Lagos presenta un vacío a investigar en cuanto a que no incluye los usos y costumbres en sus planteamientos; con ello, la revisión de la bibliografía ha ayudado en identificar la tendencia de los especialistas en el tema de gobernanza. La mayoría de los trabajos sobre la gobernanza, analiza desde la perspectiva corporativa y el dinamismo en la toma de decisiones entre actores de la sociedad local, del gobierno central y del mercado (Andrew y Cardinal, 2001, p. 1; Porras y Zavala, 2012). 
En estos trabajos, se ha planteado la gobernanza como un tema central para entender los procesos sociales en cuanto interpreta las relaciones espontáneas e informales entre agentes de diferente índole. Otros trabajos consideran la gobernanza como una respuesta de la sociedad civil a los cambios y crisis del Estado después de la Guerra Fría (Calame, 2003; Paquet, 1998). Dichos cambios y crisis permitieron que fueran involucrados otros actores del sector privado como del mercado en la toma de decisiones. En el caso de los Grandes Lagos, la participación de los actores privados, no pueden llevarse acabo si se excluyen los usos y costumbres.

Tomar los usos y costumbres como bases de la gobernanza, significa remontar a las civilizaciones más antiguas para entender el papel que desempeñan en el aprendizaje comunitario que Kooiman llama aprendizaje colectivo (2003). Asimismo, el estudio de los cambios contextuales es importante, para entender cómo la gobernanza se adapta a las transformaciones del tiempo y del espacio, pero para le caso de los Grandes Lagos, no hay mucha investigación académica sobre la gobernaza. En ese marco general de análisis, las publicaciones disponibles han centrado la discusión en dos enfoques de la gobernanza: el descriptivo y el normativo. Dichos enfoques se refieren a los gobiernos en red, la eficacia, ineficacia y el logro de las metas (Calame, 2003; Porras, 2016, p. 32).

En cuanto a los usos y costumbres existe un vacío que se debe al hecho de que la problemática de la gobernanza en la región, fue primero planteada para acompañar las reformas estructurales que el mercado necesitaba en la década de los noventa. Dichas política de reformas estructurales fueron planteadas por el Banco Mundial afin de abrir los sectores productivos como la agricultura, la industria minera a las compañias internacionales. Esos hizo que Ruanda y República Democrática del Congo establecaran acuerdos y tratados favorables a los mercados.

\section{Los usos y costumbres como esencia de la gobernanza en países posbélicos}

Plantear los usos y costumbres como esencia de de la gobernanza en los países posbélicos, es un desafio, porque los usos y costumbres tienen elementos tradicionales que cuestionan la gobernanza tal como la jerarquía. Por lo tanto considerar los usos y costumbres como base de la gobernanza, 
implica moverse entre tradición y modernidad, aunque no sea algo nuevo porque los antiguos griegos y romanos, consideraban los usos y costumbres como un elemento importante en la gestion de la Res Publica. La Grecia de Platón es un ejemplo para explicar las discusiones sobre las fronteras entre la tradición y la modernidad. ¿El Ágora no representaba ese lugar de encuentro entre lo antiguo y lo nuevo? Para los griegos, el Ágora era un lugar para discutir los problemas sociales, político, económico, religioso etc. Así, el Ágora era un espacio de diálogo, aprendizaje y de toma de decisiones.

Para Platón la tarea de gobernar debe ser reservada a las personas justas aunque el individuo estaba en centreo de la democracia griega. Un elemento importante de la Ágora, retomando el decir de Talavera (2012) era la autonomía. La autonomía era el motor de las decisiones políticas y la República estaba encima de todo. En este contexto, la política y los usos y costumbres estaban ligados.

Los usos y costumbres en los Grandes Lagos tienen un carácter conservador. Los habitantes de esa región han guardado sus formas propias de autogobierno y se rigen por sus sistemas normativos. La organización persistente de los pueblos de Ruanda como de la República Democrática del Congo, en sus usos y costumbres, se institucionalizaron desde el periodo de colonización, hasta en la actualidad. Existe una forma de gobierno gobierno local que depende de un jefe tradicional; esos gobiernos son de carácter heredero a parte de encargarse de los asuntos políticos, se ocupan de la religión, la conservación de la tradición, de la justicia etc.

Sin embargo, después del genocidio ruandés de 1994, la cuestión de usos y costumbres se volvió muy sensible, debido a que algunos conflictos armados en la región habían tenido su origen en aspectos étnicos (Kisimbou, 2006, p. 2). En los usos y costumbres, algo ha sobrevivido, a pesar de los fenómenos de la evolución de la tecnología y de la globalización. Citando a Barbe (1995), es el espíritu de pertenencia a una comunidad (p. 96). Existe una consciencia de los pueblos de los Grandes Lagos para conservar sus normas y su identidad. 
Si para Barbe (1995) la estatalización puede describir la comunidad internacional en donde cada Estado conserva su identidad propia los usos y costumbres, estos son elementos distintivos de los países de los Grandes Lagos (p. 96-97). En cada país existe la presencia de pueblos con su organización particular. Cada uno tiene su identidad, su espacio vital y su lengua.

En efecto, los usos y costumbres se relacionan al concepto de comunidad en cuanto a que son expresión de una organización de lo político, religioso, cultural, civil, económico y religioso. Es un sistema comunitario de procuración y administración de la justicia. Estos elementos muestran que los usos y costumbres van más de las expresiones físicas de las personas que cualquier otra cosa, porque implican también una identidad espiritual en su relación con el medio ambiente. Los usos y costumbres son una forma concebir el mundo.

De lo anterior, habrá que saber si la formación de los Estados modernos en el caso de Ruanda y de la República Democrática del Congo ha potenciado los usos y costumbres o sólo los consideran como una realidad existente. Aunque reconociendo el hecho de que en los Grandes Lagos, la diversidad de los usos y costumbres son una realidad viva, el fortalecimiento de la autoridad del Estado debería pasar por ahí. En este contexto, los actores políticos tendrían que identificar los elementes comunes de las comunidades para forjar una identidad nacional. También, la gobernanza podría ser, pensando a partir de los elementos que comparten gran parte de las comunidades que conforman cada uno de los dos países.

En la actualidad, como advierte Sow (1982) el contexto ha cambiado. Los usos y costumbres están amenazados por la élite política occidentalizada (p.11). Este encuentro de entre una realidad externa con los usos y costumbres locales no puede destruir la identidad de los pueblos sino que hace que los habitantes de los Grandes Lagos siga siendo el mismo abriéndose a la nueva realidad.

Sin embargo, la perspectiva de Maquiavelo (1999) está en desacuerdo con la visión platónica de la política. Para él, la política y la ética son dos mundos separados. La política tiene una 
dimensión independiente en cuanto su objetivo es el de conservar el poder. Mientras para Immanuel Kant (2002), la política tiene un carácter ético. Immanuel Kant introduce así la dimensión ética en la gobernanza aunque no haya estudiado la gobernanza como tal.

Tambéin hay que mencionar aquí que los griegos son inspiradores de los valores democráticos. La visión griega ponía énfasis en la vida de la polis, de la comunidad. Este volor pueder parecer contrario a la visión capitalista centrada en el individuo y pocas veces en la comunidad. Actualmente la tendencia es primacía de lo privado sobre lo colectivo. A pesar de esas controversias, el ser humano es un ser capaz de socializar.

En efecto, en Ruanda como en la República Democrática del Congo, la sociedad está organizada sobre las bases de los jefes tradicionales y de las colectividades frutos de los usos y costumbres ancestrales. Ésta organización durante y después de la colonización, ha sido integrada en las constituciones republicanas de dicho países. La organización social basada en los usos y costumbres, permitió a cada pueblo entenderse y definir su autonomía en questiones económicas, políticas y sociales. A nivel regional, la gobernanza en término de autonomía, basada en usos y costumbres, fue la creación de dos instituciones de alcance nacional y regional, que implicó a muchos actores. Un caso local para resolver los problemas nacionales fue el modelo jurídico ruandés para juzgar a los responsables de genocidio conocido como Gacaca y el documento de mecanismo de seguimiento de los acuerdos de paz sobre la República Democrática del Congo en Ádisa Abeba (Accord, 2013).

Todavía cabe señalar, los diferentes mecanismos creados en las últimas décadas posconflicto en Ruanda como en la República Democrática del Congo que tuvieron la finalidad el fomento del desarrollo económico y social. Para hacer el seguimiento del cumplimiento de los acuerdos, cada país nombró delegados para acompañar los esfuerzos regionales de pacificación.

Después del genocidio de 1994 en Ruanda, el gobierno de ese país utilizó una institución tradicional basada en la consulta de la sociedad llamada Gacaca. Ésta congreba a los ciudadanos juntos con los actores políticos para decidir sobre el futuro de los que habían participado en el 
genocidio. No se necesitaba un grado académico sino en la convivencia cotidiana de los habitantes (Ingelaere, 2009, p.34). El Gacaca viene de las tradiciones autóctonas derivada de la estructura social ruandesa que tomó lugar de las prácticas importadas para entender ese pueblo. Se puede entender también como una costumbre democrática que se construye sobre los métodos consensuales. Habría que decir también que la democracia participativa ruandesa, es una forma pacífica de resolver los problemas del pueblo para el pueblo (Reyntjens, 1990).

La implementación de esta jurisdicción tradicional en Ruanda, se debe al entendimiento de los problemas de genocidio desde la gobernanza local, implementado por el gobierno de ese país. La óptica de esta tradición facilitó la reconciliación de las comunidades y de las familias enemigas. El éxito de Gacaca en Ruanda fue la reconstrucción de una identidad nacional que se había destruido durante el genocidio. Esta práctica jurídica tradicional permitió lanzar los programas de desarrollo que el país necesitaba.

\section{Crisis del Estado y aprendizaje colectivo}

La crisis del Estado, la promoción del mercado junto con la incapacidad de resolver de forma rápida las cuestiones sociales justifican el interés por el estudio de la gobernanza. Sin embargo, lejos de ser una teoría de resolución de problemas, el tema de gobernanza regional aparece inscrito en una novedosa reflexión sobre la nueva forma de gestión de los asuntos públicos centrada en la incorporación de actores estatales y no estatales. De la misma manera que los cambios se han observado en otras regiones del mundo, en los Grandes Lagos la ola democratizadora ha obligado a los gobernantes a integrar los actores de la sociedad civil en la gestión de los asuntos públicos, aunque no se pueda hablar de gobernanza regional en ese sentido.

En efecto, el concepto de gobernanza desde la perspectiva neoliberal se refiere a las reformas del Estado. Una filosofía que tomó peso a partir del fin de la Guerra Fría en la era de la globalización financiera (Talavera, 2012, p.27). Esta dinámica mundial ha hecho que los actores 
implicados aprendan de la experiencia de los demás. Algunos de ellos provienen de los pueblos que han fortalecido sus tradiciones culturales y que se organizan mediante los usos y costumbres.

Hay que mencionar además que el interés de la gobernanza, obedece al papel que ésta desempeña en la acción pública local. En el pasado, el Estado había monopolizado la orientación de la acción pública. En la actualidad, la sociedad civil se ha vuelto un actor importante para exigir más transparencia y rendimiento de cuentas. Conforme a eso, la gobernanza ha intervenido en el cambio del esquema fundador de la acción pública.

Cabe destacar que la acción pública está estrechamente vinculada a la gobernanza como forma de gobierno. Un elemento importante de la gobernanza es la cooperación entre todos los actores implicados. La cooperación es posible cuando existe la participación de la ciudadanía y de los demás actores del mercado, del sector público y privado. También, la presencia de la ciudadanía y su participación en la acción pública va más allá de la construcción de las instituciones democráticas (Porras, 2012). Por lo que la cooperación es la mejor vía para la búsqueda de solución a los problemas públicos.

En efecto, como la gobernanza implica la participación de la población, en el ámbito de lo local, ha asumido la responsabilidad de procesar las demandas inmediatas de la sociedad en cuanto a los servicios básicos. De manera semejante, la gobernanza local se ha vuelto un espacio público donde los usos y costumbres han servido como vehículo de la información, que alcanza las comunidades retiradas cuando transita sobre la cotidianidad de cualquier grupo social. En el caso de los Grandes Lagos Africanos, la participación de los actores locales, ha adaptado formas distintas en función de la organización política, social y cultural local.

Este ejemplo bastó para ilustrar lo dicho con el ámbito local.

En los Grandes Lagos, los gobiernos centrales han buscado un acercamiento directo con la ciudadanía creando provincias más pequeñas para responder a los problemas administrativos de la población local. En el caso congolés, existe desde la colonización un reconocimiento de los jefes tradicionales como vectores de los usos y costumbres. Esos jefes tradicionales administran la 
colectivida y colaboran directamente con el gobierno y las organizaciones regionales e internacionales.

Sin embargo, los usos y costumbres de la región de los Grandes Lagos, están aún lejos de ser fundamento de las políticas centralizadas de los Estados por la preeminencia de la población urbana sobre la rural. También, las recientes políticas de descentralización puestas en marcha no pusieron énfasis en la transferencia de recursos a los gobiernos locales. Pero la heterogeneidad de los pueblos como la resistencia de los grupos de poder local, han frenado la aspiración a la gobernanza local y regional.

De acuerdo con Porras (2012), la gobernanza local conforma un tipo particular de gobierno cuyo eje está centrado en la construcción de nuevas modalidades de intervención y articulación más participativas y cooperativas entre los distintos actores e instancias institucionales de las sociedades. Esta forma de interacción -según Porras-, establece un sistema complejo porque no permite entender el papel de los actores implicados.

Aunque la interacción de los actores es la clave en la gobernanza local, en los Grandes Lagos Africanos, no se ofrece la garantía de una gestión pública exitosa. El gobierno local parece olvidar los usos y costumbres de los pueblos y responde a las necesidades del gobierno central y de las políticas neoliberales del mercado. En esta lógica, la responsabilidad de lo local se limita a acompañar al Estado en la operación de las políticas en el contexto de la cooperación internacional para el desarrollo.

Aunque lo que propone la gobernanza es el cuestionamiento de la sociedad jerárquica en los países como Ruanda, Burundi y República Democrática del Congo, la construcción social es jerárquica. Esa jerarquización social dificulta la toma de decisiones que defiende los intereses locales. Algunos actores sostienen que la gobernanza, en algunos países, no ha terminado con la jerarquización de la ésfera política, debido a que las decisiones de los actores más poderos son tomados en consideración en detrimento de los actores débiles (Porras, 2016, Hufty, 2010). Los 
actores más favorecidos en el momento de toma de decisión son los del mercado apoyados por el Estado.

Desde la propuesta no jerarquizada en la toma de decisiones (Porras y Zavala, 2012), la gobernanza desplaza los polos de poderes. En el caso de las estructuras jerárquicas, el poder político, económico y social, está controlado con los jefes de la etnia (Andrew y Linda, 2001, p. 13). En ese contexto, la gobernanza local es compleja: cada actor trata de gobernar, sin caer en la ingobernabilidad. Éstos son la esencia de la estructura social de los pueblos de la región. Algunos de sus valores ancestrales se trasmiten de forma oral de generación a generación y constituyen una forma de aprendizaje sobre lo cual la gobernanza local tiene sus bases.

Para entender el aprendizaje colectivo que requiere la gobernanza local, algunos autores sugieren una aproximación teórica organizacional (Paquet, 1998, p.4; Andrew y Linda, 2001, p.13). Max Boisot que luego retoma a Paquet propone dos dimensiones del aprendizaje colectivo: la primera dimensión se focaliza sobre la estructura de las ideas de transacción y la segunda dimensión enfatiza la forma del proceso de aprendizaje. En la estructura de las ideas, cada estructura de transacción corresponde un conjunto de características. Por lo que existen organizaciones sociales la información queda codificada y para decodificarla hay que ser miembre la misma organización. De la misma manera, existe un mundo de burocracia, en él, la información es abstracta y codificada en forma de normas y sólo está disponible para los miembros de la organización, es decir la información no se difunde (Paquet, 1998).

Sin embargo, la estructura de las ideas de transacción tiene otro mundo donde la información está difundida. Es el mundo del mercado. En su primera etapa se presenta como una información codificada y coordinada por una mano invisible. En realidad, es la etapa donde la está divulgada y codificada al mismo tiempo porque el mercado difunde la información que quiere.

La segunda etapa que Paquet considera importante en el aprendizaje colectivo son los procesos del mismo. Los procesos de aprendizaje se articulan sobre una dimensión cognitiva y sobre la difusión del conocimiento. La estrategia para conseguir el conocimiento aquí va de la exploración 
a la difusión de la información concreta. Es una etapa en la cual la información sirve para resolver los problemas locales. El alcance de la difusión de la información es más grande porque se dirige a la sociedad entera.

En efecto, en los procesos de aprendizaje la cultura desempeña un papel importante porque sirve de vehículo de los valores morales. La evolución de la cultura permite tambén la evolución del aprendizaje colectivo. Su punto máximo de evolución se expresa en la modificación de los usos y costumbres cuando éstos integran otras formas de organizaciones sociales provenientes de otras sociedades. Es de esta forma que se definen y cooperan los individuos.

De lo anterior, los usos y costumbres como proceso de aprendizaje colectivo contienen los dispositivos para la construcción de instituciones: económicas, políticas y ambientales en donde se genera el conocimiento y las normas. De la misma manera, las instituciones procesan la información para la gobernanza local. Sin embargo, los usos y costumbres causan un problema de valores porque la organización social no es estática. Los valores culturales se transforman con el tiempo, pero a veces toman mucho tiempo en adaptarse a la nueva realidad.

Los años posindependencia en Ruanda como en la República Democrática del Congo, se caracterizaron con gobiernos dictatoriales. Ellos introdujeron en sus respectivos países métodos que respondían a sus beneficios. El poder político estaba en sus manos, por lo que elaboraban mecanismos para garantizar su longevidad en el poder a través de la información abstracta y codificada. Esta forma de gobernar en la región, se consolidó sin tomar en cuenta los cambios que estaba produciendo en la sociedad.

La consecuencia de esta forma de gobernar en la región fue el deterioro del Estado. Se desintegraron sistemáticamente las formas de organización basadas en la difusión de la información. Los usos y costumbres que fundaban la sociedad se destruyeron, como los contratos morales y los tipos de relaciones entre clanes (Paquet, 1998). Sin embargo, la gobernanza tanto en los sectores privados, públicos como cívicos estaba evolucionando hacia una estructura menos abstracta, menos codificada y la población local empezaba a compartirse informaciones. 
En el decir de Pierre Calame se produjo el desfase entre los Estados y la sociedad por las dos velocidades diferentes que caracterizaron la región de los Grandes Lagos (Calame, 2003, p. 39). Los gobiernos se habían alejado de los usos y costumbres sobre los cuales todo el poder económico, político y civil, estaban fundados. La ciudadanía formaba un grupo aparte. Hay dos causantes de este desfase, de un lado la rapidez de la evolución social que cambia las demandas de la ciudadanía mientras que el sistema de regulación va muy lento. Del otro lado, la misma sociedad se transforma y los antiguos modelos de gobierno y de políticas públicas ya no responden a los problemas de la época.

De todas las formas para entender la evolución de la gobernanza local en la región, exige considerar del papel que desempeñan los usos y costumbres porque éstos hacen entender la monopolización del poder para unos cuantos. En efecto, los usos y costumbres de los pueblos bantú no dan lugar a una oposición a los jefes tradicionales porque es a través de ellos el Estado y el mercado tienen acceso al pueblo. Pero esta forma de concepción choca con la filosofía del mercado que promueve la competencia entre los actores.

En este contexto, la capacidad de intervención de los gobiernos se vio limitada en el ámbito público. Frente a ese fracaso, el reconocimiento por la sociedad civil de la incapacidad de los actores políticos en resolver los problemas sociales fue un impulso para presionar a los diferentes gobiernos especialmente en Ruanda. Ese país fue el motor de muchos cambios sociales que vive la región hoy en día. Los nuevos actores que emergieron de la sociedad civil o de los grupos rebeldes, consideraron los cambios como frutos de los fracasos de los gobiernos anteriores. Para Saoumi (1998), el fracaso del gobierno consiste en no llevar a cabo los proyectos que se plantea (p.164).

En el marco de la cooperación internacional para el desarrollo, la gobernanza local se vuele la solución para sanar el contexto en el que se mueven todos los actores del cambio. En el decir de Saoumi (1998), todos los actores se involucran en un juego de competitividad en donde cada uno es un desconocido en presencia del otro. Sus objetivos, estrategias, formas de actuar y sus maneras de 
pensar no pertenecen a un mismo código, pero buscan el desarrollo de la comunidad local (p. 164165).

La teoría del otro o de la diversidad de los actores que plantea este autor, tiene sus raíces en los usos y costumbres de cada uno de los actores y exige precauciones en las posturas. Sólo una norma común debe guiar a los tomadores de las decisiones en ese contexto de cooperación. Por ello, el Estado sigue siendo el actor principal para determinar los lineamientos de la cooperación entre actores. El éxito de la cooperación en este sentido, no nada sólo reside en los cambios a llevar a cabo, sino también en la lectura del conocimiento de cada uno de los actores.

Es evidente que la gobernanza permite la cooperación entre diferentes actores. También le da al Estado su lugar dentro de los dinstictos agentes que participan en la toma de decisiones. En el caso de los Grandes Logos, la gobernanza ha tenido carácter neoliberal porque le da peso a los valores promovidos por el mercado. En este caso, la teoría y la práctica de la gobernanza sigue la ruta definida para las instituciones financieras. Para esas instituciones, la gobernanza incluye la exigencia de democratización, el respeto de los derechos humanos, una buena gestión de los asuntos públicos. (Andrew y Linda, 2001, p.59).

\section{La gobernanza como perspectiva de cooperación internacional y conflicto social.}

Plantar la gobernanza como criterio de la cooperación internacional en los Grandes Lagos, de parte de los países donantes de la ayuda al desarrollo, corresponde al cambio contextual en las últimas décadas. Eso es la emergencia de los nuevos actores que transfiguran el contexto de la cooperación internacional y los conflictos de valores de los usos y costumbres locales. Dichos conflictos corresponden al papel que desempeña el Estado y el mercado (Paquets, 1998, Andrew y Linda, 2001, p. 88). Otros autores asocian el conflicto local con la crisis del Estado y la ideología del mercado que restringen la libertad de elección de la política nacional. (Martínez, 2005, p. 90).

En efecto, la cuestión de gobernanza no fue bien recibida por los gobiernos en la región porque implicaba democratizar los regímenes, introducir a nuevos actores en la toma de decisiones. 
Eso significaba revisar la comprensión de la administración de los asuntos públicos y redefinir el papel de cada uno a pesar de que el Estado quedaba con el monopolio de la toma de decisiones.

En los Grandes Lagos, la perspectiva que tomó la gobernanza se inspiró del marxismo. Esta teoría se basaba en los movimientos sociales hasta a las revoluciones populares que más tarde se convirtieron en grupos armados en contra de los gobiernos en el caso ruandés como congolés. Dichos movimientos se nutrían del pensamiento desarrollista como fue el caso de algunos países de Latino América (Furtado, 1965). Sin embargo, no se cuestionó el papel que debía jugar la implementación de políticas públicas, sino que se necesitaba un cambio de modelo de hacer política. Hay que subrayar aquí que la gobernanza como perspectiva de cooperación entre actores, no ofreció una nueva noción de hacer política en la región, sino que se concibió como una teoría intermediaria para entender la restructuración de los procesos sociales.

Para comprender los movimientos sociales en la región, es necesario tener en cuenta del contexto en el que surgieron. Esos movimientos nacieron de la ola democrática de los años post Guerra Fría que sacudieron el continente africano, pero también se pueden entender como una respuesta crítica a los regímenes dictatoriales. Hay que observar que los años noventa, en Ruanda, se caracterizaron por una serie de luchas internas para definir las políticas de desarrollo en todos los ámbitos. En fondo se encuentra la disputa por el poder de nuevos actores que nunca tuvieron cargo político dentro de los gobiernos anteriores.

No cabe duda, de que estas tensiones reflejaban la inestabilidad institucional de los propios gobiernos centrales. La economía estaba golpeada. El desempleo de la masa, la migración forzada paralizó una parte de los sectores productivos y otros fenómenos sociales ponían aprueba el marco institucional. Se trazaba así una gobernanza cuyo aprendizaje colectivo se estaba iniciando.

Después de analizar el papel de los movimientos sociales que exigieron el cambio en los regímenes políticos, ahora hay que tomar en cuenta los problemas que la gobernanza enfrenta en su adaptación a los modelos tradicionales arraigados en los usos y costumbres locales. Por lo que 
entender sus implicaciones y limitaciones permite destacar cuatro pilares para guiar el análisis a la luz de Hamel (2001):
a. La gobernanza y los cambios contextuales
b. La nueva gobernanza y su adaptación al contexto social
c. La cooperación y el conflicto
d. El aprendizaje (p.88).

Cuando Hamel (2001) presenta estos cuatro pilares no pretende analizar todos los cambios sociales que afectan el Estado y el mercado, sino que considera algunos de ellos. Para él, los cambios obedecen a la ausencia del Estado en la vida pública (pp. 88-89). Para este autor, la gobernanza en un contexto de conflicto, sólo puede darse a través de la caída de los modelos tradicionales. Desde luego el análisis de Hamel considera que los cambios contextuales son factores de adaptación de la gobernanza en los usos y costumbres. Éstos no son un impedimento para el desarrollo de gobernanza, sino son recibidores de los cambios del mundo interconectado. En ese contexto, la gobernanza como la plantea el mercado se vuelve un elemento externo a los usos y costumbres que integra una organización social prexistente.

De lo anterior, hay que deducir que la interdependencia de los actores es resultado de todo el cambio que acontece en la realidad internacional. De la misma manera, la transformación en la política internacional de cualquiera forma incide en la realidad local. Por lo tanto, la gobernanza local forma parte de dichos cambios y transformaciones que los Grandes Lagos están experimentando. A pesar de que es un proceso lento, el crecimiento del pluralismo social y cultural es cada vez más de actualidad poniendo a luz la incapacidad del gobierno tradicional en poner orden social.

\section{a) Gobernanza y cambios contextuales:}

Los cambios sociales que acompañan la gobernanza se deben a la emergencia de un mundo cada interconectado. Esos cambios implican la decadencia de las instituciones políticas, el nacimiento de 
una nueva cultura política y la definición de un nuevo regimen políca (Hamel, 2001, p. 88). En otro orden de cosas, el debate sobre los cambios contextuales constituye la noción de gobernanza porque la gobernanza no puede explicarse sin hablar de cambios sociales.

La decadencia de las instituciones políticas tradicionales se asocia al avance de la evolución tecnológica y de los medios de comunicación. Con ella, la sociedad es cada vez más pluricultural. En consecuencia, las instituciones tradicionales y representativas se vuelven muy limitadas para enfrentar la nueva realidad. Éstas son cada vez más incapaces de ofrecer a los ciudadanos un cuadro de representación, de aprendizaje cultural y de integración social estable. Retomando a Crozier y a Friedberg (1977), la fragmentación del sistema político y social está a la base del desarrollo de nuevos sistemas de acción concreta. Es precisamente la cuestión del contexto dentro de la cual emerge el segundo proceso: la nueva cultura política.

La nueva cultura política es el resultado de la decadencia de las instituciones que no responden a las demandas de la nueva sociedad. Para Hamel (2001), hay que romper con las representaciones tradicionales que pone adelante un pensamiento abstracto sin tomar en cuenta las formas concretas de la vida social (p. 91). Además, la diversificación de los actores en la gestión de la vida pública conduce la democratización de la acción pública. La democratización de la acción pública es una invitación al repaso de la constitución de la vida en la comunidad y lleva a la definición de otro régimen de la acción pública.

La definición de otro régimen de acción pública es el resultado de ajustes políticos que exige los actores implicados. Se da generalmente entre el gobierno y los ciudadanos. Eso significa revisar los mecanismos y procedimientos de toma de decisiones. El régimen de acción pública tiene que ser pragmática para responder a las demandas sociales. La alianza que se crea entre gobierno y ciudadanía permite implementación, evaluación y estabilidad. En fin, si los tres procesos constituyen la gobernanza y el cambio contextual en el nivel decisional, el régimen pragmático es el más apto para entender la naturaleza de los conflictos entre interés particular y general. 


\section{b) La gobernanza y su adaptación al contexto social}

La noción de gobernanza responde a las transformaciones del contexto social como se ha ido mencionando hasta aquí. También se debe a la elaboración de políticas locales, nacionales e internacionales que responden de forma rápida y eficaz a las demandas de la ciudadanía. Eso muestra que los modelos de gestión anterior en el contexto cambiante han tenido efectos positivos en los sectores públicos donde han sido aplicados.

Frente a las transformaciones, la primera tarea del sector gubernamental es ajustarse al pluralismo social y cultural. Sin embargo, la adaptación es un trabajo que exige la redefinición de las fronteras entra lo público y lo privado. De esta manera, hay que hablar de gestión policéntrica que va de lo local, nacional, regional y supranacional. Es allí que Paquet (1998) recurre a la cuestión pragmática del gobierno.

Actualmente en los Grandes Lagos, el contexto social de gobernanza local representa un cuestionamiento de los antiguos modelos de la gestión pública. En ese caso, hay un abandono de la gestión desde arriba hacia abajo, para dar prioridad a los intereses de las instituciones locales. De una manera concreta, se asiste a la creación de mecanismos locales y regionales en la gestión de los conflictos en el contexto social: el tribunal Gacaca en Ruanda y el Mecanismo Conjunto para el Seguimiento para el caso regional. En este contexto, la gobernanza local se ejerce entre lo público y lo privado. El sector público se presenta como el actor que tiene todo el poder decisional y el sector privado como poseedor de recursos.

De lo anterior, la gobernanza y el contexto social dependen de la colaboración entre el sector público y el sector privado. Así, la filosofía colaborativa de las dos entidades se orienta hacia el funcionamiento administrativo y corporativo integrando las prioridades de todas las partes.

\section{c) La cuestión de la cooperación y del conflicto}

En la mayoría de los escritos sobre gobernanza y cooperación internacional la cuestión de conflicto suele ser ausente. Muchos son los actores que sostienen que la gobernanza es un criterio 
importante para que haya cooperación internacional (Calame, 2003). Otros autores piensan que este ámbito los conflictos suelen ser de valores. La mayor parte de las veces, esos conflictos se refieren a los principios éticos y morales. Es el caso de algunos conflictos de carácter étnico.

De la misma manera, otros conflictos en términos de cooperación suelen ser de carácter económico. En este contexto se inscriben los largos conflictos de los Grandes Lagos. Algunos grupos se sienten marginados en comparación con otros. Hay que mencionar que no todos los conflictos se resuelven con la negociación, también que el contexto conflictual excluye de la mesa de negociación algunos actores.

Si se considera la realidad que hasta aquí se vino analizando acerca de la colaboración entre el sector público y privado, se puede afirmar que no siempre hay un acuerdo en la forma de resolver los asuntos públicos. En este contexto, se genera un conflicto en el momento de definir las prioridades de cada grupo. Cuando existe una alianza entre muchos actores, las prioridades tienden a desaparecer y los ciudadanos pueden esperar los resultados positivos a sus demandas. La problemática del beneficio encamina hacia el aprendizaje colectivo.

\section{d) El aprendizaje.}

En el texto de Gilles Paquet (1998), existe una relación entre el aprendizaje colectivo y el conflicto. Para este autor, la gobernanza como generadora de aprendizaje colectivo entra en conflicto con las normas existentes que sea al nivel urbano o al nivel estatal. La expresión visible de esa realidad es la creación de los movimientos sociales para exigir respuestas de la parte del gobierno o del mercado. Los actores de estos movimientos exigen las condiciones que permiten a cada individuo realizar sus elecciones. Por lo que la cuestión de la subjetividad es lo que se logra con el aprendizaje colectivo.

Para concluir, los usos y costumbres de los pueblos es el único valor normativo que queda después de los conflictos armados. Los conflictos armados dejan los Estados sin ningún poder estatal, poder ejecutivo, legistivo y judicial. Algunos países como Ruanda para poder reconstruirse tuvo que recurrir a la tradición de sus habitantes retomando Gacaca como forma para juzgar a los 
responsables del genocidio. El caso de la República Democrática del Congo en sus diferentes conflictos han intervenido muchos actores y mecanismos. Algunas instituciones jugarons un papel importante para que se llegara a un acuerdo de paz entre ellos están la Iglesia Católica, las Naciones Unidas y la Unión Africana. Se ha mostrado que la gobernanza implica la participacion de actores de diferentes índoles, mercado, gobierno y sociedad civil.

\section{Referencias:}

Andrew, C. y Linda, C. (2001). La démocratie à l'épreuve delà gouvernance, Canada: Université d'Ottawa.

Anyang, P. (1999). Institucionalización del gobierno democrático en el África subsahariana. Estudio de Asia y África. 108; Vol. XXXIV, 13-32.

Barbe, E. I. (1995). Relaciones Internacionales, Madrid: Ed. Tecnos, p. 96.

Calame, P. (2003), La démocratie en miettes, Pour une révolution de la gouvernance, Paris, Ed. Charles Léopold Mayer.

Comunidad Económica de Estados de África Occidental. (2016). Assistance technique pour la revision des prescriptions de gestio pour le developpement des ressources en gaz du lac kivu http://cepgl.org/IMG/pdf/avis_a_manifestation_d_interet_version_francaise.pdf

Chiasson, G. y Savard, S. (2001). La gouvernance des services sociaux: quelle participation pour les organismes communautaires ?, Politique et sociétés, vol. 20, nos 2-3.

Crozier, M.; Friedberg, E. (1977). L'acteur et le système, Paris, Seuil.

Hamel, P. (2001). La gouvernance: une perspective valable pour repanser la cooperation et les conflicts. En Andrew, C. y Linda, C. (2001). La démocratie à l'épreuve delà gouvernance, Canada: Université d'Ottawa, p. 87-99.

Hufty, M. (2010). Gobernanza en salud pública: hacia un marco analítico, en Revista de Salud pública 2010. 12 sup (1): 39-61. 
Ingelaere, B. (2009). Les juridictions gacaca au Rwanda, Sweden.

Kant, I. (2001). Sobre la paz perpetua, España, Ed. Tecnos.

Kooiman, J. (2003). Gobernar en la gobernanza. Gobernanza, democracia y Bienestar social, Barcelona.

Kitsimbou, X. (2006). La démocratie et les réalitpes éthniques au Congo, Paris: Université Nancy II.

Maquiavelo, N. (1999). El Príncipe. elaleph.com [Versión electrónica]. Recuperado de https://ocw.uca.es/pluginfile.php/1491/mod_resource/content/1/EI_principe_Maquiavelo.p df

Martínez, A. (Coord.) (2005). La gobernanza hoy, 10 textos de referencia, Madrid, Ed., Instituto Nacional de Administración Pública.

Mena, J. E. (2013). Los fundamentos político-administrativos de la gobernanza, México, Ed. Fontamara.

Olvera, M., L. et al. (2013). Gobernanza global en un mundo interconectado, México, Universidad Autónoma de Baja California.

Paquet, G. (1998). La gouvernance en tant que manière de voir: le paradigme de l'apprentissage collectif, disponible en http://www.gouvernance.ca/publications/98-29.pdf

Porras, F. y Zavala, J. S. (2012). “Participación ciudadana y gobernanza local como forma de gobierno en México". En: Redes y jerarquías, noviembre 2012, Vol. I, México, p. 137-158.

Reyntjens, F. (1990). Le gacaca ou la justice du gazon au Rwanda, Bélgica: Universidad de Anvers.

Saoumi, T. (1998). "Participer à la gouvernance”. En: Les Annales de la recherche urbaine 80-81, p. 163-171.

Sow, A. (1982). Prolegómeno, en Balogun, H. et al. (editores). Introducción a la cultura africana: aspectos generales, España: ediciones del Serbarl, p.11.

Talavera, R. G. (2012). Usos y costumbres y participación política en México, México: Tribunal Electoral del Poder Judicial de la Federación. 
Tony, J. (2014). Algo va mal, México: Santillana Ediciones Generales.

United Nations Pacemaker (2013). Accord-cadre pour la paix la sécurité et la coopération pour la République démocratique $d u$ Congo et la región 2013. Recuperado de http://peacemaker.un.org/sites/peacemaker.un.org/files/DRC_130224_FrameworkAgreeme ntDRCRegion.pdf 